\title{
Prática de campo em paleo-rotas e o uso desta como proposta de ensino de Geociencias na educação básica
}

\begin{abstract}
Resumo: 0 presente artigo tem como intuito apresentar a experiência de uma prática de campo na região dos campos gerais especificamente nas cidades de Castro, Ponta Grossa e Tibagi-PR, tendo esta abordagem paleontológica de uma dada paleorota como um proposta de ensino de geociências na educação básica usando para tanto a prática de campo. De forma geral, esse trabalho teve como base a compreensão paleontológica relacionada a saídas de campo feitas com o grupo de pesquisa Palaios da Universidade Estadual de Ponta Grossa (UEPG), na região dos Campos Gerais especificamente nas cidades de Castro, Ponta Grossa e Tibagi-PR,Brasil. Como interesse foi feito o reconhecimento dos afloramentos fossiliferos e consecutivamente a coleta e classificação de alguns exemplares. Estes, através da taxonomia e a tafonomia, serviram de material para definir a estratificação cronológica dos achados. Com uso da discussão teórica dos elementos abordados, e visto a pouca abordagem da Paleontologia na Educação Básica, buscou-se também uma possível transposição das idéias de paleo-rotas para o Ensino Fundamental e Médio, enfatizando a importância da pesquisa na Paleontologia e a conservação de sítios com o pressuposto de uma educação ambiental, propiciando assim, ambientes alternativos para o ensino.
\end{abstract}

\section{Practice field in paleo-routes and use this as a motion for teaching basic education in Geosciences}

\begin{abstract}
This article is intended to present the experience of a practice field in the region of the general fields specifically in the cities of Castro, Ponta Grossa-PR and Tibagi, this approach has given a paleontological paleorota as a proposal for teaching basic education in the geosciences using for both the practice field. Overall, this study was based on the understanding related to paleontological field trips made with the research group Palaios, State University of Ponta Grossa (UEPG), in the Campos Gerais region specifically in the cities of Castro, Ponta Grossa and Tibagi-PR, Brazil. As interest was made the recognition of fossiliferous outcrops and thereafter collection and classification of some specimens. These, through the taxonomy and taphonomy, served as material to define the stratification of chronological findings. With use of the theoretical discussion of the elements discussed, and seen little of Paleontology approach in Basic Education, also sought a possible implementation of the ideas of paleo-routes for elementary and high school, emphasizing the importance of research in palaeontology and conservation sites with the assumption of an environmental education, thus enabling environments for alternative education.
\end{abstract}

Fernando Fernandes*

Thales Ravel Hetka

Okonoski ${ }^{* *}$

Ian Navarro de Oliveira

Silva**

* Mestrando em Geografia Gestão do Território: Sociedade e Natureza da Universidade Estadual de Ponta Grossa

** Mestrando em Geografia Gestão do Território, UEPG, Universidade Estadual de Ponta Grossa PR

Palavras- chave: Paleontologia; Geociências; Educação Ambiental; Educação Básica.

Key-Words: Paleontology; Geosciences; Environmental Education; Education 


\section{Introdução}

O presente trabalho constitui-se em uma pesquisa qualitativa, sendo utilizadas as técnicas de pesquisa bibliográfica e de campo (MARCONI \& LAKATOS, 2005). A pesquisa bibliográfica sobre os estudos geológicos e paleontológicos do Período Devoniano e a situação do ensino de temas de Geologia na Educação Básica, serviram de suporte para a análise e discussão dos resultados obtidos na pesquisa.

A pesquisa de campo foi realizada no mini-curso "Prática de Campo: Paleontologia do Devoniano dos Campos Gerais", sob coordenação do Professor Dr. Élvio Pinto Bosetti, como cumprimento aos créditos do Programa de Pós-Graduação em Geografia, Mestrado em Gestão do Território, da Universidade Estadual de Ponta Grossa.

Com base no trabalho de campo e no estudo da Paleontologia dos Campos Gerais do Paraná se expõe certa revisão bibliográfica da temática e a exposição de conceitos e técnicas envolvidas para a tentativa de uma contextualização espacial e temporal do assunto.

A prática de campo, desenvolvida em três dias, foi estruturada em observação e coleta de materiais, acompanhadas de explicações em campo. Os afloramentos visitados fazem parte do roteiro geológico estabelecido por Matsumura (2010) e/ou são estudados por integrantes do grupo de paleontologia estratigráfica Palaios (2010), nos municípios de Castro, Tibagi e Ponta Grossa, na Bacia Sedimentar do Paraná.

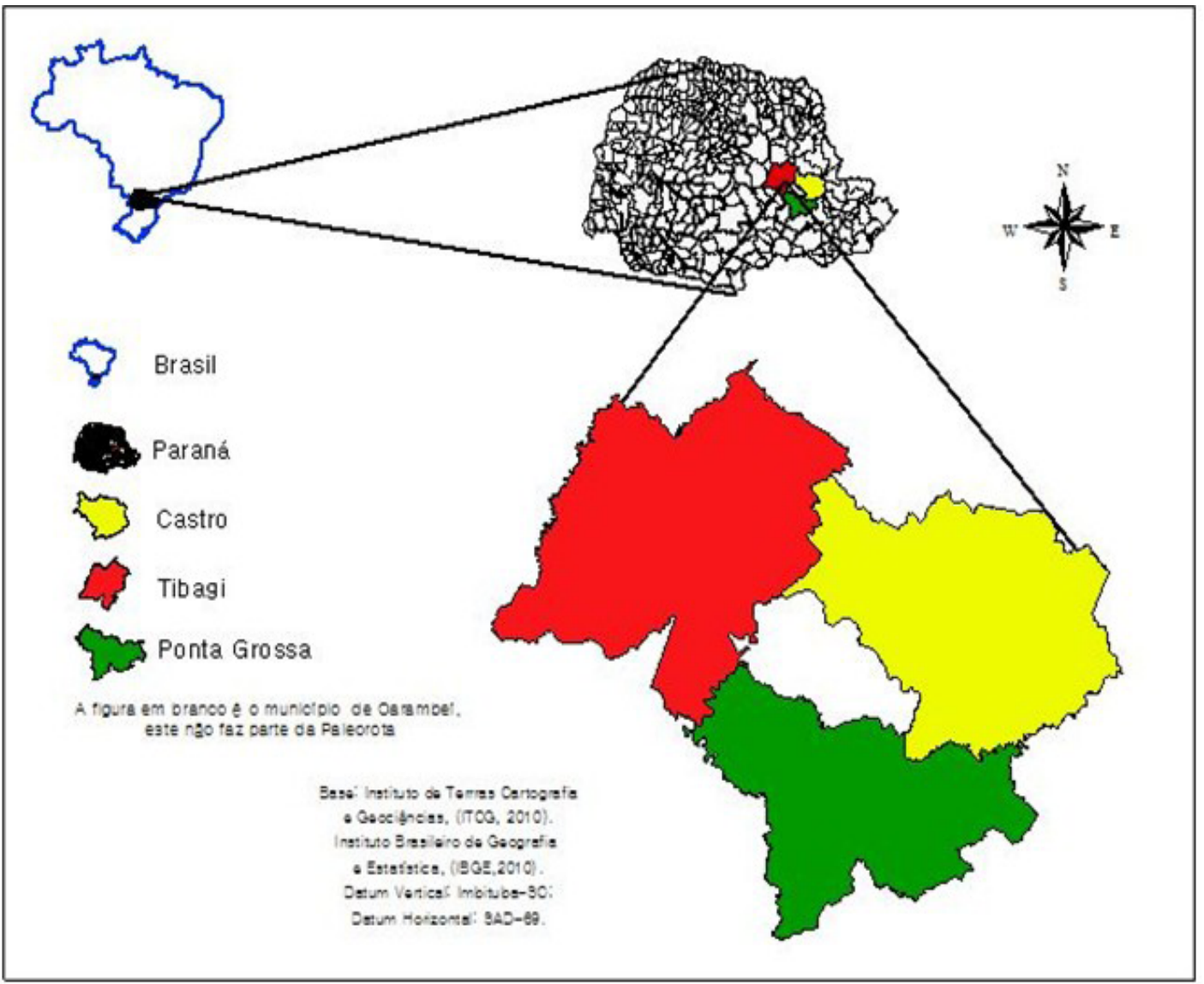

Geografia Ensino \& Pesquisa, v. 16, n.2 p. 63 - 78, maio/ago. 2012

Prática de campo em paleo-rotas e o uso desta como proposta de ensino de Geociencias na educação básica
Figura 1- Localização dos municípios da paleo-rota. Org:FERNANDES, 2010.

Durante a prática de campo foram observadas seções de duas Supersequências da Bacia do Paraná (MILANI, 1997 apud BOSETTI, 2010), além de sua base que é constituída pela Bacia de 
Castro. A primeira Supersequência da Bacia do Paraná, denominada Rio Ivaí, é caracterizada pela Formação lapó e a segunda como Grupo Paraná, sendo explorados nesse trabalho os Membros Tibagi e São Domingos dentro da Formação Ponta Grossa (Devoniano Médio e Superior). Os pontos visitados seguiram, na sua maior parte, uma ordem paleocronológica.

O presente artigo tem como intuito apresentar a experiência de uma prática de campo na região dos campos gerais especificamente nas cidades de Castro, Ponta Grossa e Tibagi-PR, tendo esta abordagem paleontológica de uma dada paleorota como um proposta de ensino de geociências na educação básica usando para tanto a prática de campo

\section{Prática de campo: a Paleontologia dos Campos Gerais Paranaense}

Estudos sobre a evolução do Planeta Terra, tanto em relação a aspectos biológicos, geológicos, paleontológicos, entre outros, são ordenados principalmente por Eras, Períodos e Épocas, que marcam etapas de evolução e de transformação no planeta e dos seres que o habitam.

Nesse contexto explica-se que o continente Laurentia colidiu com a Báltica formando a Euramérica que, juntamente com a Sibéria e o Gondwana, compõe as terras emersas do globo Bosseti (et al 2010). Santos (2004, p 48) expõe que "as mais extensas transgressões marinhas do Fanerozóico da América do Sul estão registradas no Devoniano",

Pelo Devoniano entende-se como um dos períodos da Era Paleozóica, entre 416 milhões e 354 milhões de ano atrás, caracterizado por grande sedimentação continental intercalada com depósitos marinhos e por intensas movimentações geológicas, essa dinâmica resultou na formação de diversos ambientes com inúmeras formas paleontológicas.

Por meio das análises científicas de datação e estudo paleontológicos atuais, estas formas podem auxiliar na compreensão da dinâmica do globo e das formas biológicas existentes, além de suas mudanças fenotípicas e genotípicas. Inúmeros fósseis vêm a contribuir na caracterização das áreas e no estudo destas.

Em se tratando da Formação Ponta Grossa como a Formação Furnas do Devoniano inferior estas compõem parte da Bacia do Paraná, conjunto litoestratigráfico Grupo Paraná (LOBATO, 2005), sendo esse sobreposto por rochas da Formação Itararé através de contatos discordantes na sobreposição de elementos sedimentados angulares.

Formada pelos Membros Tibagi, Jaguaraíva e São Domingos, a Formação Ponta Grossa situa cronologicamente acima da Formação Furnas, (Lange \& Petri, 1967 apud MELO et al 2004) e abaixo da Formação Itararé.

A prática de campo foi constituída por 8 pontos de observação e coleta de materiais, incluindo os afloramentos das Formações Furnas e Ponta Grossa - Membros Tibagi e São Domingos. Neste trabalho serão destacados alguns pontos que demonstraram ser relevante, devido a sua importância estratigráfica e/ou a qualidade das amostras fósseis encontradas.

O primeiro ponto - ponto 1 de Matsumura (2010) - que serão destacados é caracterizado pelos afloramentos rochosos localizados próximos à cidade de Castro, nas margens da PR - 351, classificados como pertencentes à Bacia de Castro (figura 02).

Sobre a Bacia de Castro considera-se que é mais antiga que a Bacia do Paraná, encontrandose estratigraficamente abaixo desta constituindo sua base ou escudo. Caracterizado pela presença de rochas metamórficas e magmáticas esse afloramento, embora geologicamente relevante, do ponto de vista paleontológico é pouco importante por não possuir fósseis.
Geografia Ensino \& Pesquisa, v. 16, n.2 p. $63-78$, maio/ago. 2012

Fernandes, F.; Okonoski, T. R. O.; Silva, I. N. O. 


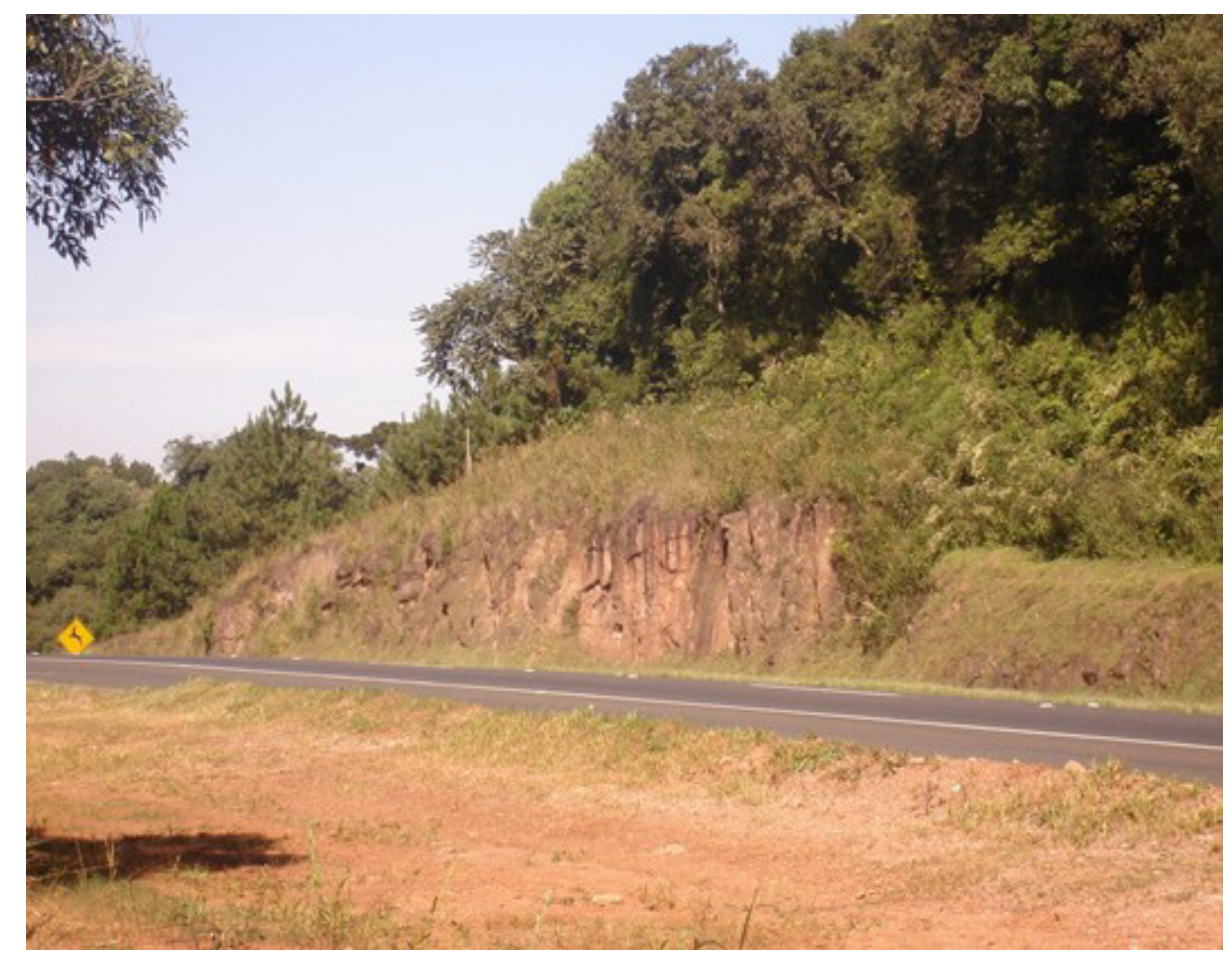

Figura 02 - Afloramento da Bacia de Castro

Org: FERNANDES, 2010.

Didaticamente é um afloramento importante enquanto explicação geológica, embora ao se tratar de fósseis não se torna um afloramento interessante. Essa característica pode ser aproveitada em trabalhos de campo no intuito de se trabalhar a formação do Estado e consequentemente dos planaltos e outras geoformas.

A bacia sedimentar do Paraná segundo Bosseti (et al,2010):

Geografia Ensino \& Pesquisa, v. 16, n.2 p. $63-78$, maio/ago. 2012

Prática de campo em paleo-rotas e o uso desta como proposta de ensino de Geociencias na educação básica
Possui um registro estratigráfico incompleto compreendendo o Período Ordoviciano Superior ao Neo-Cretáceo, atingindo aproximadamente $7000 \mathrm{~m}$ de espessura em seu eixo deposicional. De acordo com Milani et al. (2007 a) a Bacia originou-se como um golfo aberto para 0 mar Panthalassa, através do movimento convergente entre 0 continente Gondwana e o assoalho oceânico do Panthalassa que no Fanerozóico, contribuiu para o fechamento progressivo da Bacia do Paraná até sua continentalização completa.

Em relação à idade da seqüência Paraná, Assine (1996) divide-a em três seções estratigráficas deposicionais a partir de unidades litoestratigráficas de Lange e Petri (1967), sendo a base a sequência Lochkoviana abrangendo a Formação Furnas, unidades I e II, seguida da sequência Praguiana-Eifeliana a qual é constituída pela Formação Furnas unidade III, Formação Ponta Grossa, Membro Jaguariaiva e Membro Tibagi. No topo a sequência Eifeliana-Frasniana, abrangendo a Formação Ponta Grossa, topo do Membro Tibagi e Membro São Domingos (BOSSETI, 2010).

Quadros (1999), por meio das associações de acritarcas encontradas em cada membro indicou a idade correspondente a cada Formação sendo Praguiana-Emsiana para o membro Jaguariaiva, Emsiana-Eifeliana para o membro Tibagi e para o membro São Domingos a idade Eifiliana- Neofameniana. Grahn (1999), baseando-se em registros de quitinozoários apresentou idades diferentes as quais foram apresentadas por Quadros, (apud, SCHEFFLER et al, 2007), sendo respectivamente Praguiana-Emsiana, Emsiana e Emsiana Eofransniana. Contudo através de conhecimentos e estudos estratigráficos, Bergamaschi (1999), (apud BOSSETI, et al 2010), 
aproveitando também estudos dos quitinozoários de Grahn, reconheceu seis diferentes seqüências deposicionais Siluro-Devoniana, para a Formação Ponta Grossa e Formação Furnas, (SCHEFFLER, 2007; BOSSETI, et al 2010).

Os afloramentos localizados nas margens da rodovia PR - 340, entre os municípios de Castro e Tibagi, foram o segundo ponto de observação - ponto 2 de Matsumura (2010), caracterizado como contato entre a Formação lapó - de origem glaciogênica - e a Formação Furnas (figura 03).

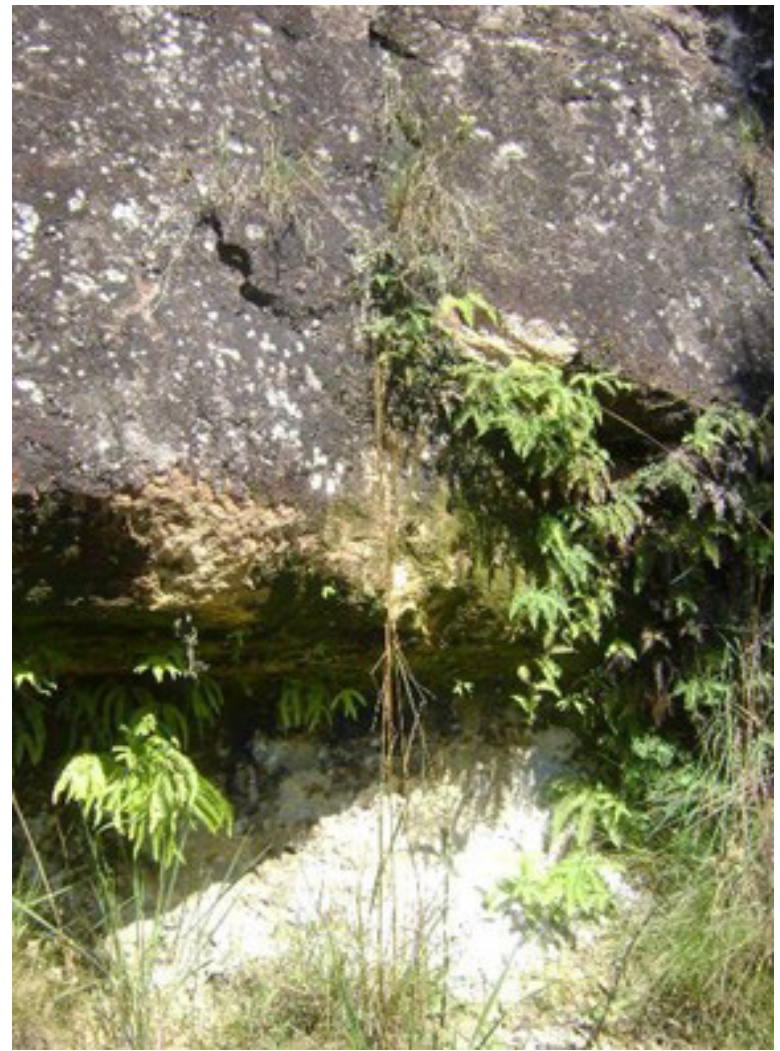

Figura 03 - Contato entre a Formação lapó (inferior) e a Formação Furnas (superior) Org: FERNANDES, 2010.

A Formação Furnas assenta-se sobre a base cristalina ou Formação lapó, sendo a unidade mais antiga da Bacia do Paraná (MAACK 1947 apud BOSSETI, 2010). Essa Formação na seção tipo a oeste da cidade de Castro é uma estrutura geológica caracterizada por duas camadas respectivamente de material glacial de drift, e mais recente material acinzentado sem origem vulcânica de fase pré-devoniana. "A idade da Formação Furnas é considerada como se estendendo do Neo-Siluriano (Pridoliano) ao Eo-Devoniano (Lockoviano/ Praguiano), segundo Assine (1996) e Bergamaschi (1999)" (MELO, 2004).

Sua Formação é motivo de discussão teórica, alguns autores citam de a Formação ter origem marinha como é o caso de Bigarella et al. (1966) e Lange \& Petri (1967), enquanto uma proposição de uma formação fluvial é entendida por Northfleet et al. (1969) e Schneider et al. (1974). Assine et al. (1994) propuseram que as Furnas foram depositadas em formatos de deltas os quais seriam construídos por rios entrelaçados, já Borghi (1996) e Assine (1996) consideram a origem devido a retrabalhamento marinho de paleo-correntes costeiras (apud MELLO, 2004).

Na Formação Furnas, a primeira do Grupo Paraná dentro de uma escala estratigráfica, foi possivel observar em campo que a área é teoricamente formada por processos deposicionais a qual contém no local arenito grosso e deposições de seixos angulosos, os quais aludem que 0 ambiente fonte de formação localizava-se próxima da área de deposição e que ali ocorriam variações de

Geografia Ensino \& Pesquisa, v. 16, n.2 p. $63-78$, maio/ago. 2012

Fernandes, F.; Okonoski, T. R. O.; Silva, I. N. O.

ISSN 2236-4994 | 67 
intensidades deposicionais decorrentes de mudanças climáticas. Essa formação comporta uma discussão quanto à sua origem, se fluvial ou marítima costeira.

Esse ponto é rico em detalhes para se trabalhar em Geociências, além de explicações sobre os elementos físicos do local, pode-se fazer prospecção local e coleta de material a qual propicia um contato entre observador e fonte de pesquisa. A instigação pelas ciências em muitos casos é fortalecida pelo contato ou visualização do assunto.

No próximo afloramento, o terceiro - ponto 4 de Matsumura (2010) -, próximo à entrada da cidade de Tibagi, é caracterizado como seção-tipo de contato entre a Formação Furnas e a Formação Ponta Grossa (figura 03). Sendo um contato heterolítico, contém variações nos estratos de sedimentos e energia na fase de formação. É considerada uma área de deposição com características de encontro das águas de rio com a água do mar (delta). Nesse ponto, durante a prática de campo, não foram encontrados exemplares de fósseis, embora os mesmos existam na região de contato. Um fator que dificulta a localização deve-se ao fato de que, na época de Formação, ter havido grande oscilação de energia e deposição de sedimentos oriundos da área fonte.

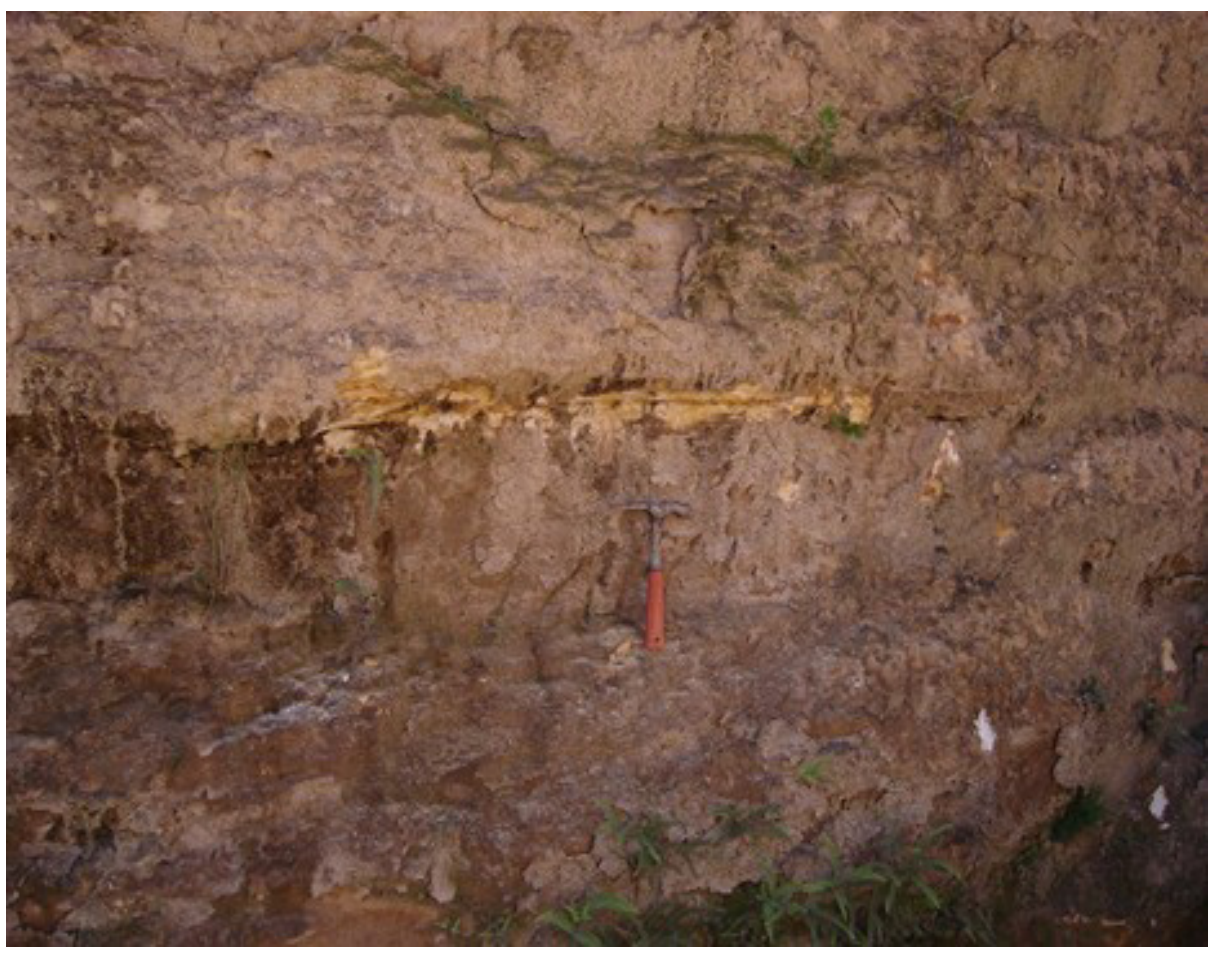

Figura 04- Contato entre a Formação Furnas (inferior) e a Formação Ponta Grossa (superior). Org:FERNANDES, 2010.

No ponto seguinte, o quarto, - ponto do grupo Palaios (2010) - próximo a uma propriedade rural denominada Fazenda Cabanha, possui folhelhos da Formação Ponta Grossa, Membro São Domingos, correspondentes ao Devoniano Médio e Superior. As buscas por fósseis nesse afloramento resultaram na localização apenas de fragmentos vegetais pouco conservados. As

Geografia Ensino \& Pesquisa, v. 16, n.2 p. 63 - 78, maio/ago. 2012

Prática de campo em paleo-rotas e o uso desta como proposta de ensino de Geociencias na educação básica rochas sedimentares superficiais encontram-se intemperizadas, causando alterações no material e influenciando na análise e classificação dos fósseis.

Na seqüência, quinto ponto, foi coletado fóssil no afloramento denominado Sítio Wolf, - ponto do grupo Palaios (2010) - do Olgivetiano. Este é caracterizado pelo efeito Lilliput, quando ocorre uma extinção em massa e poucas espécies ficam remanescentes, mas com grande população, há variação fenotípica, mas não genotípica. Nessa área foi observado também o efeito Lazarus, quando espécies aparecem em camadas inferiores, desaparecem nas intermediárias e reaparecem nas superiores (BOSSETI et al, 2010). 
O sexto ponto - ponto do grupo Palaios (2010), no afloramento São Bento (figura 05), remete ao início do Givetiano, situado no topo do Devoniano. Nessa fase de crise biótica a região apresenta depósitos de argila em águas profundas, longe das costas continentais, havendo pouca presença de fósseis.

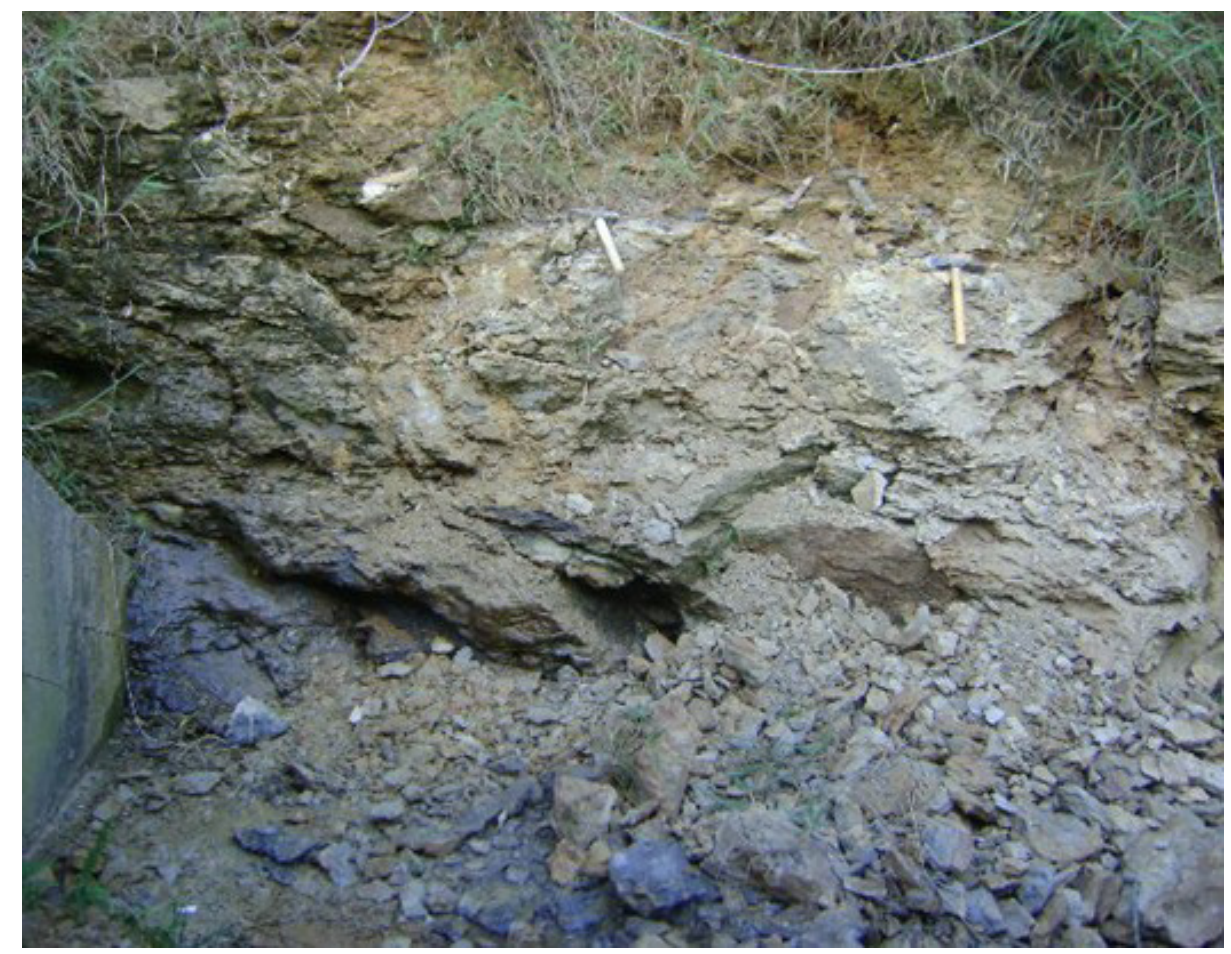

Figura 05 - Afloramento São Bento.

Org:FERNANDES, 2010.

A seção tipo Eusébio de Oliveira, sétimo ponto - ponto do grupo Palaios (2010) - apresenta o contato das camadas médio-inferior e médio-superior: Jaguariaíva - Tibagi - São Domingos (figuras 05, 06 e 07 respectivamente). Nesta seção foi realizada a coleta de fósseis utilizando o método de quadrículas adotado pelo grupo Palaios (2010). As quadrículas (figura 8), com três metros de altura e dois de largura, são prospectadas para, além de obter amostras, definir a disposição destas dentro da área analisada. Através da interpretação dos fósseis, são elaborados esboços descritivos dos fósseis encontrados.

Assine 1996 e Bergamaschi, 1999 apud (MELO, 2004), comentam que o membro Jaguariaiva "é constituído de folhelhos laminados fossilíferos e bioturbados, com lentes de arenitos finos subordinadas, depositados num contexto de plataforma marinha rasa, de idade correspondente ao intervalo Praguiano a Frasniano". Lange e Petri, 1967 (apud BOSSETI, et al 2010), citam que o contato da Formação Jaguariaiva com a Furnas é concordante gradacional e com a Itararé sendo discordante. É uma Formação fossilifera contendo bivalves gastrópodes, trilobitas, braquiópodes, em ambiente de sedimentação marinho raso, o qual teve taxa de sedimentação lenta e com pouca energia com intensa colonização bentônica do fundo, embora esses levantamentos percam sentido com os trabalhos que vieram a ser desenvolvidos com Rodrigues (2002) e Bosseti, (2004), apud Zabini, (2007).

No Membro Tibagi há presença de arenitos finos a muitos finos com lenticulares e fossiliferos, estando de forma concordante e gradacional sobre o Membro Jaguariaiva e sob 0 São Domingos caracterizado pela forma gradacional (ZABINI, 2007). Há presença de micas e de folhelhos laminados que varia a coloração de acordo o grau de intemperismo que podem estar sujeitos nos afloramentos. Para Lange e Petri (1967) apud Bosseti (2010) no Membro Tibagi há
Geografia Ensino \& Pesquisa, v. 16, n.2 p. $63-78$, maio/ago. 2012

Fernandes, F.; Okonoski, T. R. O.; Silva, I. N. O.

ISSN 2236-4994 | 69 
uma ciclicidade arenito/folhelho os quais seriam provocados por movimentos eustáticos. De forma geral, esses ciclos eustáticos foram responsáveis pela formação de estratos com características granulométricas e de formas deposicionais distintas no Membro Tibagi.

Assine e Petri (1996) apresentam o Membro Tibagi contendo arenitos grano crescentes, tendo aumento da fração areia para o topo e Bosseti (1989) acrescenta a composição fossilífera do Membro Tibagi sendo muito rica (BOSSETI, 2010). Característica essa que exemplifica a variação das intensidades deposicionais na formação geológica do membro e a localização das áreas formadoras dos sedimentos.

O Membro São Domingos, de idade Givetiana é unidade topo acima do Membro Tibagi, contem estratos laminados de cor cinza, os quais em alguns casos apresentam-se na forma de betuminosos entremeados por camadas de arenitos finos, sendo o seu encontro com o Grupo Itararé discordante (LANGE \& PETRI, 1967, apud BOSSETI et al, 2010).

Para Bergamaschi, (1999, apud ZABINI, 2007) o Membro São Domingos é o pico da máxima transgressão marinha e conseqüente deposição do período Devoniano na Bacia do Paraná.

Para Assine e Petri (1996) a transgressão acarretou em uma mudança ecológica drástica causando a extinção da fauna da Província Malvinocáfrica na passagem do Eifeliano-Givetiano. Entretanto Bosseti (2004) com uso de estudos de fósseis expõe que a fauna da Provincia Mauvinocáfrica não se extingue nessa fase e sim ultrapassa o limite do Givetiano alcançando a topossequência local no topo da Formação Ponta Grossa, compreendida pelo Frasniano, extinguindo apenas no Frasniano/Fammeniano. (ZABINI. 2007).

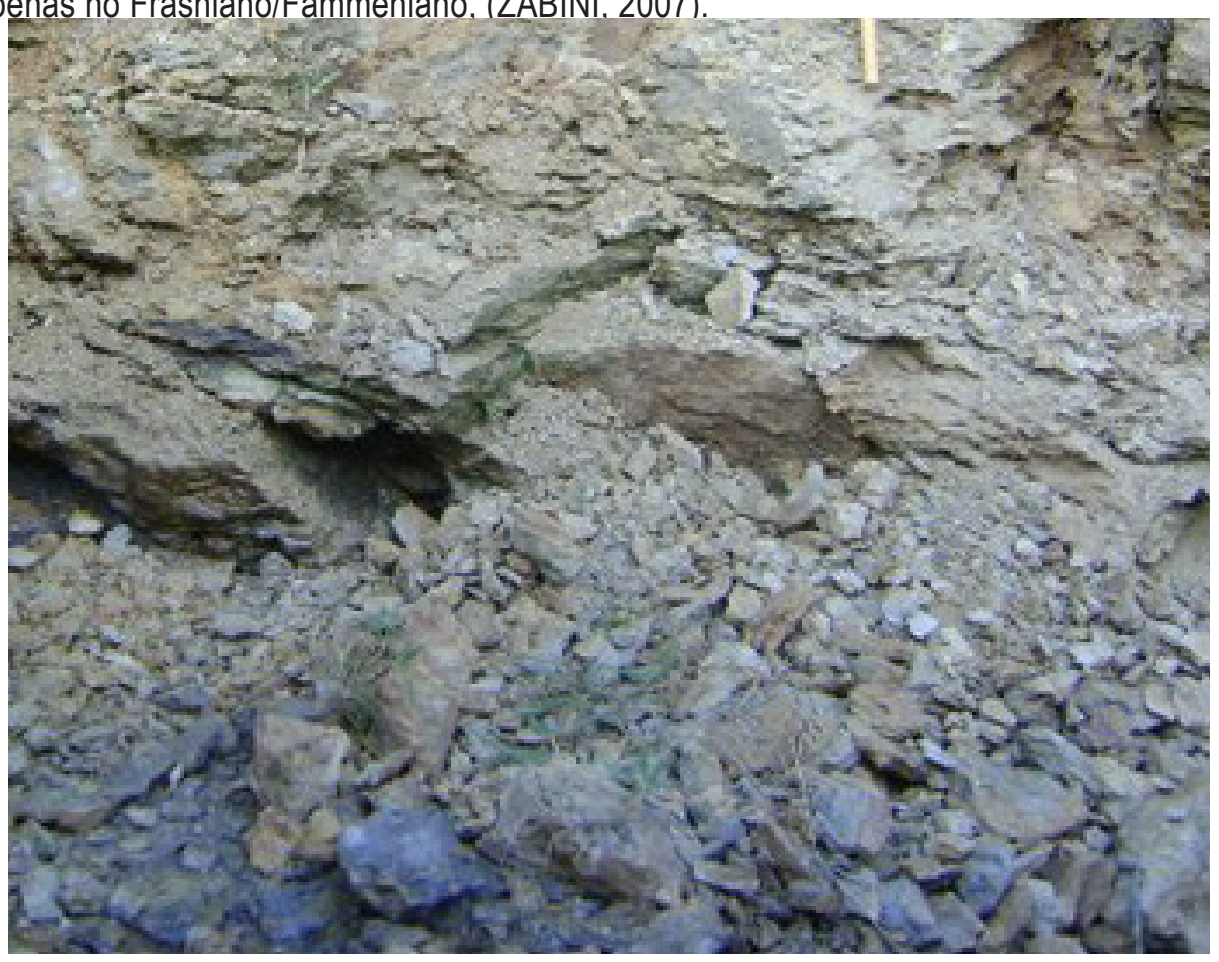

Figura 06 - Formação Ponta Grossa, Membro Jaguariaiva Org:FERNANDES, 2010. 


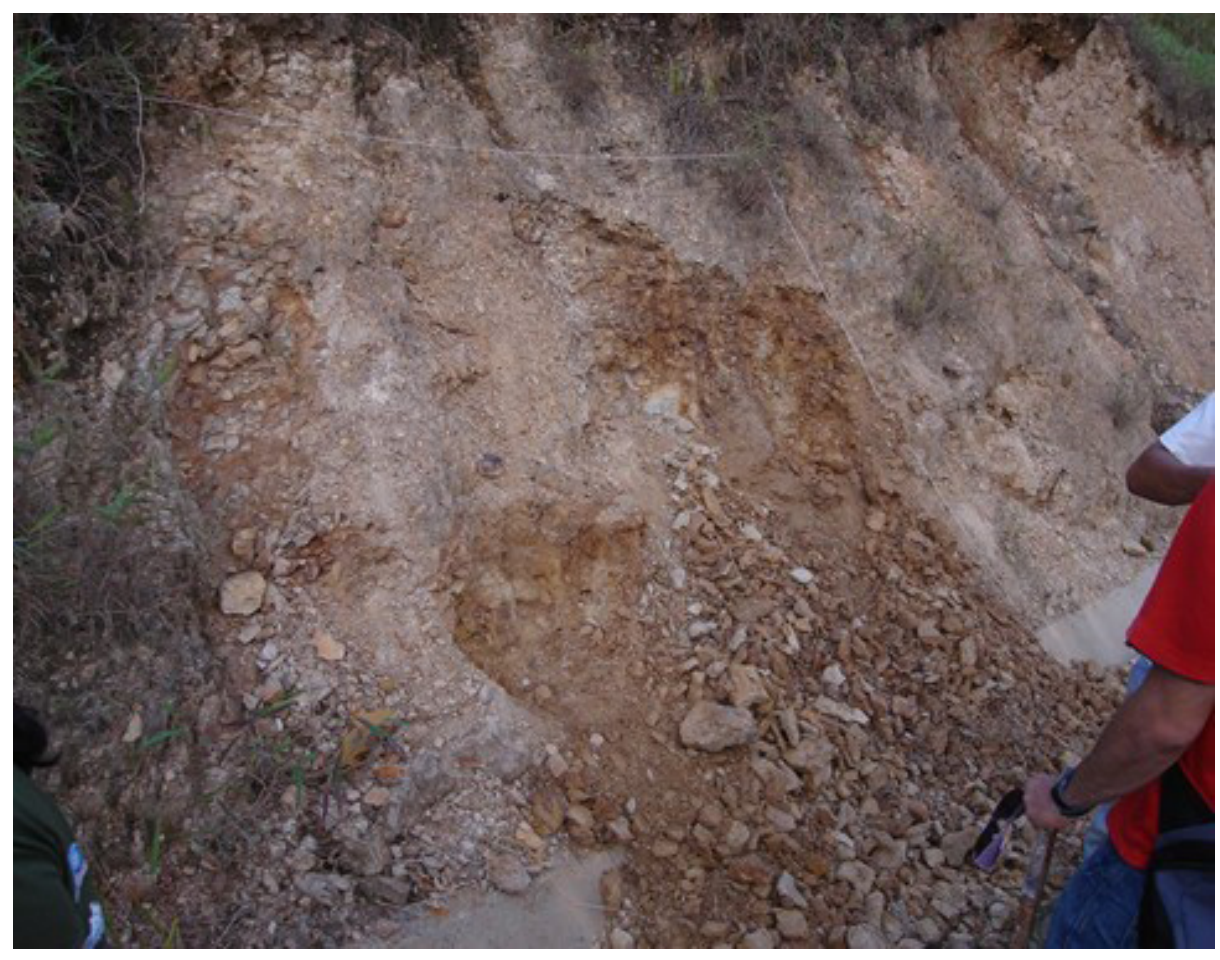

Figura 07 - Formação Ponta Grossa, Membro Tibagi Org:FERNANDES, 2010.

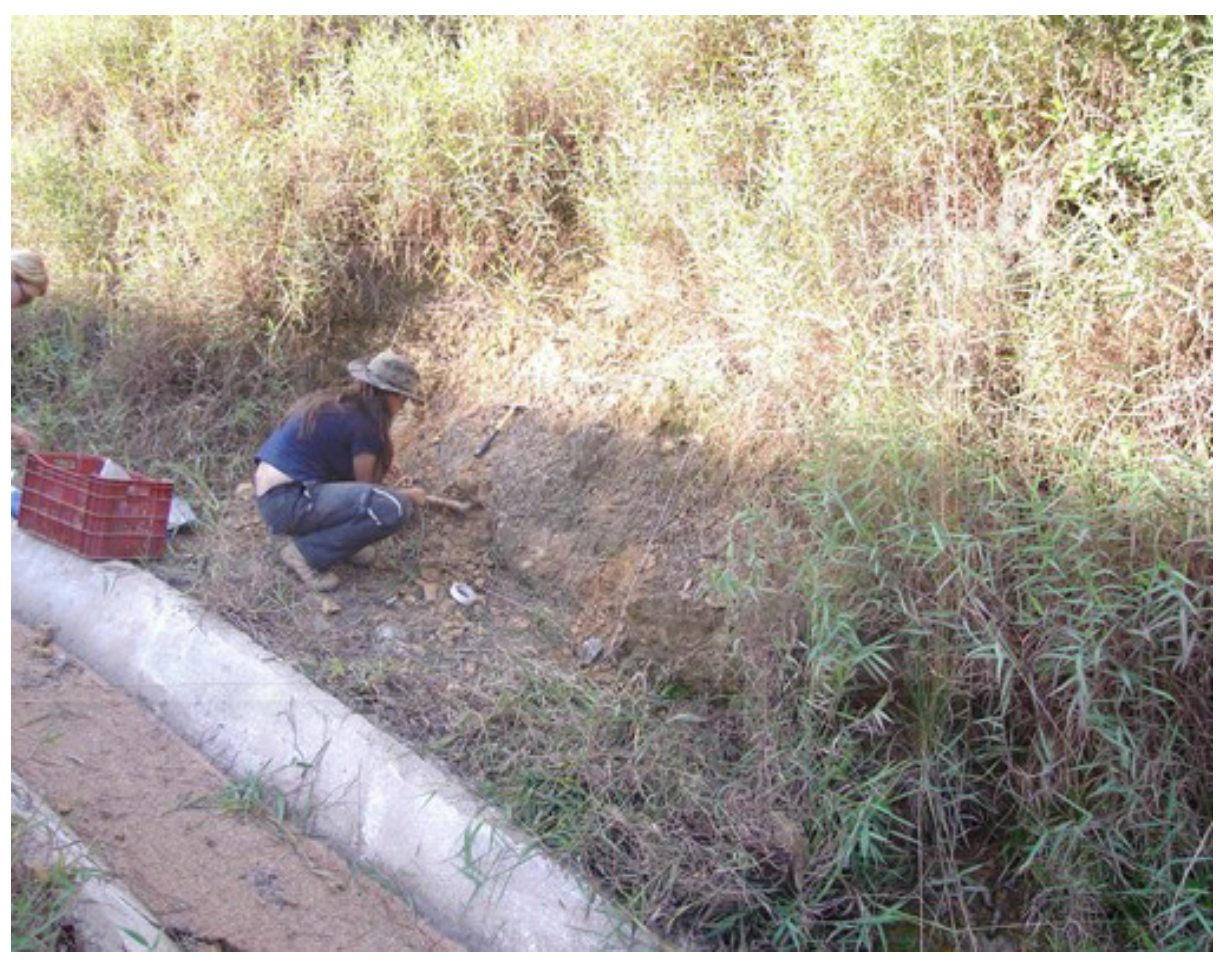

Figura 08 - Formação Ponta Grossa, Membro São Domingos Org:FERNANDES, 2010.

Geografia Ensino \& Pesquisa, v. 16, n.2 p. $63-78$, maio/ago. 2012

Fernandes, F.; Okonoski, T. R. O.; Silva, I. N. O.

ISSN 2236-4994 | 71 


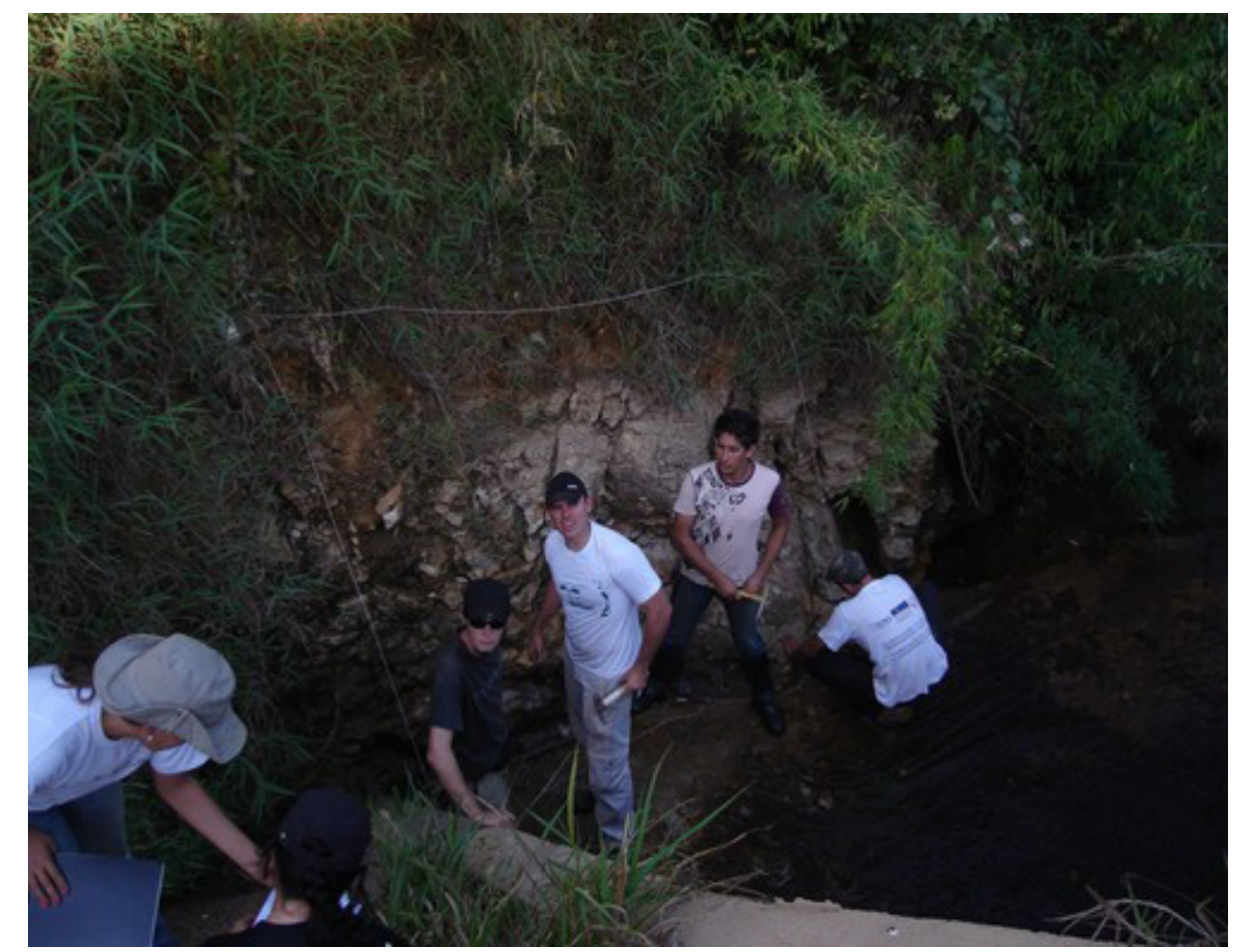

Figura 09 - Construção de quadrícula Org:FERNANDES, 2010.

Nos afloramentos do oitavo ponto - Ponto 15 de Matsumura (2010) - foram observadas estruturas heterogêneas estratigráficas curvadas formadas por deposição de sedimentos causados por ondas, em fases de oscilação de energia e deposição (figura 9), são estes os Hummocky (perfazem a mudança do padrão de ondas decorrentes de eventos de tempestades). Neste, através do método de coleta em diferentes extratos horizontais, foram encontrados braquiópodes articulados também orbiculóides.

Geografia Ensino \& Pesquisa, v. 16, n.2 p. 63 - 78, maio/ago. 2012

Prática de campo em paleo-rotas e o uso desta como proposta de ensino de Geociencias na educação básica

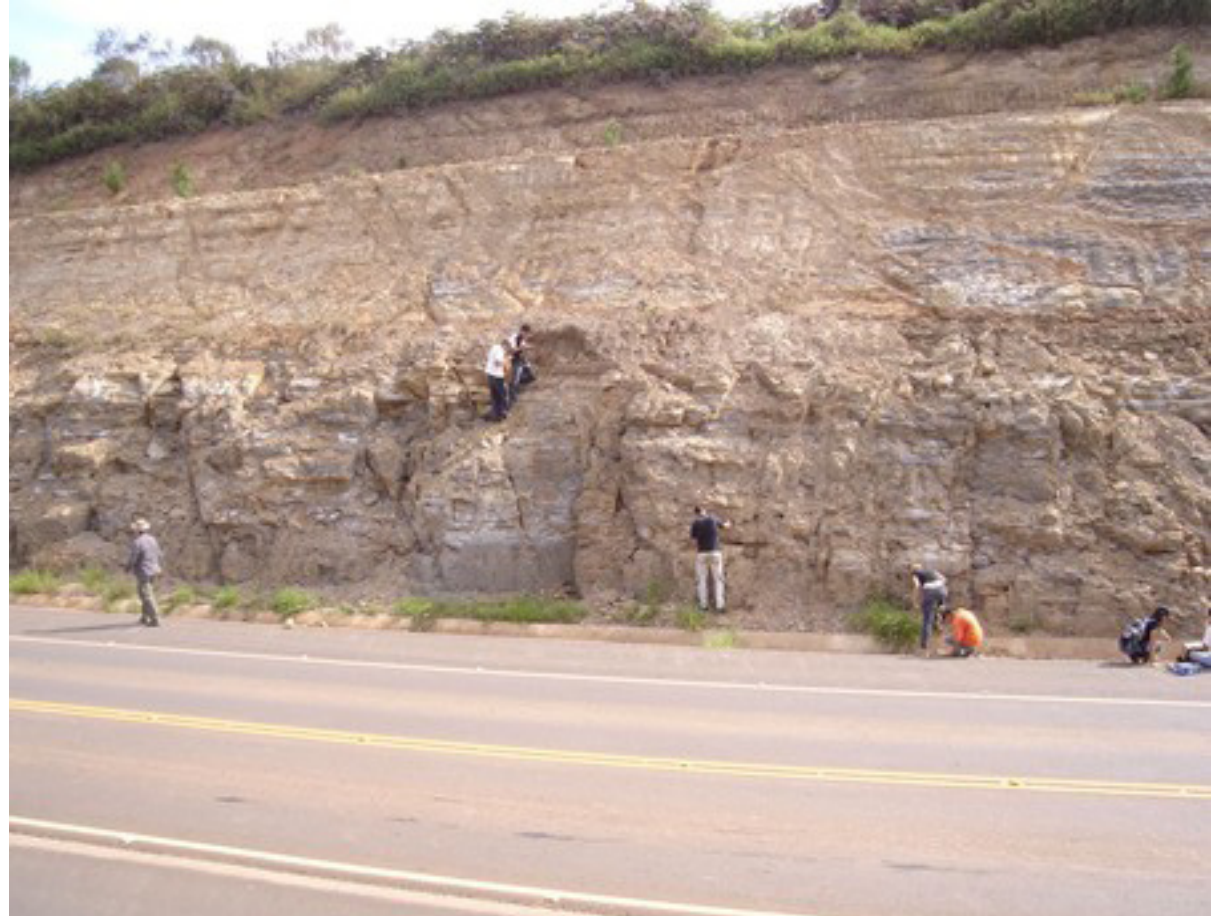

Figura 10 - Afloramento com ocorrência do efeito Hummocky Org:FERNANDES, 2010. 
O trabalho de campo oferece a possibilidade de integrar os conteúdos dispersos em várias disciplinas, significando-os e permitindo a sua compreensão, pois, tal como afirma Compiani (2007, p. 32)

\begin{abstract}
O trabalho de campo pode ser utilizado, no ensino, como estratégia em que todas as coisas podem tomar parte de um processo maior: 0 efeito holográfico. A idéia é enfrentar a dominante fragmentação do conhecimento, que bloqueia os mecanismos de análise de problemas reais ao não facilitar a relação de conceitos, procedimentos e de atitudes, trabalhados em diferentes disciplinas do currículo.
\end{abstract}

A integração entre os conteúdos de diferentes disciplinas é uma necessidade frente à modernidade, definida por Leff (2003, p. 16) "como uma ordem coisificada e fragmentada", constituinte da crise do conhecimento da qual faz parte a atual crise ambiental (SOUZA, $2000 \mathrm{e}$ GONÇALVES, 2006).

O trabalho de campo é ainda uma oportunidade de estabelecer relações entre o local e 0 global a partir do lugar, pois, "o focar para a relação global/local aponta para a necessidade das metodologias de estudos do meio e trabalhos de campo." (COMPIANI, 2007, p. 32).

A apreensão de conceitos científicos a partir do conhecimento empírico é também outra possibilidade dos trabalhos de campo que, segundo Compiani (2007, p. 30), "apontam para noções diferentes do empírico" e, para Compiani e Carneiro (1993, p. 91) contribui no "entendimento dos fenômenos e na formulação de conceitos explicativos."

Nesse sentido retomam-se as palavras de Compiani (2007, p. 43), quando afirma que

\begin{abstract}
Ao trabalhar os impactos ambientais provocados pelo descontrole do crescimento urbano acelerado, força-se a necessária relativização do papel da ciência e da tecnologia na resolução de problemas do dia a dia, pois fica evidente que os problemas ambientais são - antes de outra coisa políticos -, e isto se contrapõe à crença positivista de que a ciência é universalmente aplicável e eficaz (cientificismo). Essa visão oculta, por exemplo, a possibilidade de existir articulação entre degradação ambiental e injustiça social. Perante um ensino que tem fomentado a passividade, propõem-se a construção ativa de conhecimentos, ação, participação e tomada de decisões na solução de problemas que têm implicações políticas, sociais e ambientais.
\end{abstract}

Nesta perspectiva, espera-se que o trabalho de campo em paleo-rotas contribua para a aquisição de conhecimento e desenvolvimento de compreensão sobre o planeta Terra e seu funcionamento, através da integração de conteúdos, do estabelecimento de relações locais/ globais, da apreensão de conceitos científicos, sob a perspectivas das problemáticas ambientais contemporâneas.

Do mesmo modo, que propicie a formação de cidadãos ativos e participantes, aptos a discutir e decidir as múltiplas possibilidades de superação da situação ambiental atual que, como visto, não tem apenas implicações ambientais, mas, também, sociais, econômicas e políticas das mais importantes.

\title{
As Geociências na Educação Básica brasileira e a construção do cidadão.
}

A crise ambiental contemporânea (SOUZA, 2000; GONÇALVES, 2006) e sua constante exposição pelos meios de comunicação em massa tem, apesar de certo sensacionalismo, contribuído para resgatar a importância dos conhecimentos sobre o planeta Terra e seus complexos mecanismos de funcionamento.

Diante dos graves problemas ambientais da atualidade - desequilíbrio climático, degradação e esgotamento de recursos naturais, mesmo os renováveis, perda da biodiversidade, entre outros

Geografia Ensino \& Pesquisa, v. 16, n.2 p. $63-78$, maio/ago. 2012

Fernandes, F.; Okonoski, T. R. O.; Silva, I. N. O. 
-, que aceleram ou mesmo desencadeiam processos até então só concebidos em uma escala de tempo geológica, é cada vez mais necessário entender as dinâmicas transformadoras que atuam no planeta Terra, bem como suas intensas interações.

As Geociências, entre as quais Neves et al (2008) incluem a Astronomia, a Cosmologia, a Geologia, a Oceanografia e a Paleontologia, entre outras, tem uma grande contribuição para a aquisição do conhecimento e o desenvolvimento da compreensão necessária ao desenvolvimento intelectual de cada aluno. No entanto, como afirmam os mesmos autores, seu ensino "nos primeiros anos das escolas brasileiras ainda é muito incipiente" (NEVES et al, 2008, p. 106). Isto se torna evidente quando se observa os resultados brasileiros no teste PISA (Programa Internacional para Avaliação de Alunos) promovido pela OCDE (Organização para Cooperação e Desenvolvimento Econômico). Entre 57 países avaliados, o Brasil alcançou a $52^{\circ}$ colocação, obtendo uma média de 390 pontos em 800 possíveis. Na área "Sistema espacial e planeta Terra" - que envolve tema de Astronomia, Cosmologia e Geologia - foram obtidos 375 pontos, o pior resultado alcançado pelo país (JORNAL DA CIÊNCIA, 2010).

Os maus resultados alcançados por alunos brasileiros refletem uma sociedade que, de modo geral, não possui compreensão ou mesmo conhecimento sobre a Terra e seu funcionamento devido às fragilidades no processo educativo. Toledo et al, atribuem este fato à forma como a temática é tratada no currículo escolar, afirmando que "há apresentação dos temas nesta área como inserções dispersas, fragmentadas e desconectadas do ciclo natural em outras disciplinas escolares, como Ciências, Geografia, Biologia, Química e Física" (TOLEDO et al 2005, p. 2).

Em se tratando das séries iniciais de ensino tem-se o ensino médio como fase em que as Geociências são quase inexistentes bem como há colocação de assuntos dispersos, embora seja no ensino fundamental a ocorrência de certa concentração das Geociências nas séries iniciais. Nessa etapa a pelos alunos o surgimento de deficiências metodológicas e conceituais dados 0 enfoque feito pelas Geociências.

No Ensino Médio há certa percepção de fragmentação curricular, sendo corroborada por Carneiro et al, Toledo \& Almeida (2004, p. 3) ao afirmam que:

\footnotetext{
Noções de Geologia e Geociências dispersam-se no currículo sob vários títulos, faltando uma ordenação capaz de explicar a Terra em conjunto, desde sua constituição, origem e evolução, fenômenos interiores e superficiais, as interações das esferas (oceanos, atmosfera, litosfera, biosfera), e as profundas e diversificadas relações entre meio físico e seres vivos.
}

Geografia Ensino \& Pesquisa, v. 16, n.2 p. 63 - 78, maio/ago. 2012

Prática de campo em paleo-rotas e o uso desta como proposta de ensino de Geociencias na educação básica
As reformas curriculares por meio das DCN, (Diretrizes Curriculares Nacionais), as quais foram previstas pela LDBEN (Leis de Diretrizes e Base da Educação Nacional) na década de 90, as quais são complementadas pelas PCNs (Parâmetros Curriculares Nacionais), também da década de 1990, não superaram tal divisão curricular, em casos propiciam em certo aprofundando das especificações cientificas.

Assim, entre outros, em virtude da fragmentação e da dispersão dos conteúdos sobre a Terra e seu funcionamento, os alunos e a população brasileira, de um modo geral, apresentam pouco conhecimento e compreensão sobre os mesmos, o que tem consequências relevantes, principalmente no contexto atual, quando a questão ambiental assume importância cada vez maior.

Dentre essas consequências podemos apontar, a partir de alguns autores que o conhecimento paleontológico fica restrito a poucas instituições públicas e privadas (NEVES et al; CAMPOS; SIMÕES, 2008) e que a concepção de que os problemas ambientais são passíveis de resolução estritamente científica, sem envolver questões e decisões políticas (COMPIANI, 2007) prejudica difusão do conhecimento da temática.

A ação política, nesse sentido, constitui-se na arena, umas das opções, onde os cidadãos podem atuar com força suficiente para pressionar as grandes corporações transnacionais, os governos 
nacionais e os organismos supranacionais a reverter o processo de degradação ambiental resultante de um modelo de sociedade e de produção ecologicamente desequilibrado e socialmente injusto.

Objetivando a superação da concepção a política da problemática ambiental, alguns autores qualificam a educação ambiental como Crítica (CARVALHO, 2006), Emancipatória ou Transformadora (LOUREIRO, 2006), ou mesmo como fundamental na gestão ambiental pública ao passo de proporcionar o desenvolvimento de conhecimento e habilidades tanto individual como coletiva (QUINTAS 2004). Estas propostas têm, entre outros pontos comuns, a formação do cidadão para a ação política como pressuposta para a superação da atual crise ambiental.

Retomando a questão do currículo, Carneiro et al, Toledo \& Almeida (2004) citam reformas curriculares realizadas na Espanha e nos Estados Unidos da América, que resultaram na inclusão de temas de Geologia em nível secundário/pré-universitário. Em âmbito brasileiro, a Universidade de São Paulo - USP criou o curso de licenciatura em Geociências e Educação Ambiental com objetivo de preparar professores que:

\begin{abstract}
Participem da formação de indivíduos capazes de opinar de forma consciente sobre as questões de ocupação e uso do ambiente pela sociedade, aproximando-a, assim, do caminho rumo ao desenvolvimento sustentável e aos objetivos das diretrizes curriculares traçadas para a educação básica." (TOLEDO et al, 2005, p. 2).
\end{abstract}

Afirma Bacci (2009, p. 9),
O conhecimento em Geociências apresenta uma grande importância para o cotidiano dos cidadãos, pois abre possibilidades da sociedade tomar decisões e compreender as aplicações dos conhecimentos sobre a dinâmica natural na melhoria da qualidade de vida.

E também Carneiro et al; Toledo e Almeida (2004, p. 1), ao afirmarem a necessidade de que "[...] as questões de natureza ambiental passem a integrar o corpo de conhecimentos básicos que uma pessoa deveria possuir, para exercer, ao longo de sua vida, aquilo que se entende por cidadania responsável e consequente".

Compreende-se assim a importância do ensino contextualizado e integrado das temáticas relativas às Geociências na Educação Básica - Ensino Fundamental e Médio - como forma de permitir aos educandos adquirir conhecimentos relacionados ao funcionamento do planeta Terra. Tais conhecimentos podem permitir aos educandos participar dos processos decisórios relativos ao ambiente em que vivem.

\section{Conclusão}

0 trabalho de campo atrelado às suas mais diversas utilidades educacionais propicia a diversificação na forma de ensinar principalmente assuntos que atualmente não são tratados em sala de aula da educação de base. O despertar para a ciência, no caso tratado para a Paleontologia, ajuda a compreensão dos elementos do meio e propicia um despertar crítico dos alunos envolvidos melhorando seu desempenho em atividades complementares da escola e do dia a dia.

A obsolescência do ensino e a forma conservadora empregada por muitos professores podem ser "quebradas" com uso da dinâmica de ensino e pesquisa já em educação de base, assim 0 uso da ciência paleontológica pode propiciar uma variedade de inteligências colocando 0 aluno defronte a natureza e a possibilidade de compreendê-la.

É necessário reverter essa tendência, propiciando a formação de cidadãos conscientes, críticos e participantes das decisões políticas que influenciam na sociedade como um todo, principalmente no tocante às questões que envolvem o ambiente em que vivem.

Geografia Ensino \& Pesquisa, v. 16, n.2 p. 63 - 78, maio/ago. 2012

Fernandes, F.; Okonoski, T. R. O.; Silva, I. N. O.

ISSN 2236-4994 
Os trabalhos de campo constituem-se ainda na ocasião, por excelência, para tratar das temáticas ambientais, relacionando os problemas ambientais locais e globais e discutindo, além das possíveis soluções técnico-científicas, as questões político-econômicas envolvidas.

Propõe-se a utilização metodológica do trabalho de campo em paleo-rotas com objetivo de despertar o interesse dos alunos sobre o planeta Terra e seus mecanismos de funcionamento, propiciando a aquisição de conhecimentos e o desenvolvimento de compreensão sobre a temática.

\section{Referências bibliográficas}

BACCI, D. L. C. A contribuição do conhecimento geológico para a educação ambiental. Pesquisa em Debate, v. 6, n. 2, jul./dez. 2009. Disponível em http://www.saomarcostatuape.com.br/portal2/ pesquisaEmDebate/docs/pesquisaEmDebate_11/artigo_7.pdf. Acesso em 01 jun. 2010

BOSSETI, E.P. PRÁTICA DE CAMPO: Paleontologia do Devoniano nos Campos Gerais, 2010, Paraná. Mini-curso. Universidade Estadual de Ponta Grossa, Programa de Pós-Graduação em Geografia, Mestrado em Gestão do Território. 30h.

COMPIANI, M \& CARNEIRO; C. D. R. Os papéis didáticos das excursões geológicas. Enseñanza de las Ciencias de la Tierra, v. 1, n. 1, p. 90-98, 1993. Disponível em http:// en.scientificcommons.org/41952887 Acesso em 01 jun. 2010

COMPIANI. M; TOLEDO, M. C. M.; ALMEIDA, F. F. M. Dez motivos para a inclusão de temas de geologia na educação básica. Revista Brasileira de Geociências, Campinas, 2004. Disponivel em http://www.ige.unicamp.br/ forum/arquivos/Documentosuteis/Dez argumentosRBGFinal8000palavras.pdf Acesso em 01 jun. 2010

COMPIANI, M. O lugar e as escalas e suas dimensões horizontal e vertical nos trabalhos práticos: implicações para o ensino de ciências e educação ambiental. Ciência \& Educação, Campinas, v. 13 , n. 1, p. 29-45, 2007. Disponível em http://www.scielo.br/scielo.php?script=sci_arttext\&pid =S1516-73132007000100003 Acesso em 01 jun. 2010CARVALHO, I. C. M. Educação Ambiental: a formação do sujeito ecológico. 2 ed. São Paulo: Cortez, 2006.

GONÇALVES, C. W. P. El desafio ambiental. México, D.F.: PNUMA, 2006.

JORNAL da Ciência. Em ciência, $61 \%$ estão no pior nível. Disponível em http://www. jornaldaciencia.org.br/Detalhe.jsp?id=52818 Acesso em 01 jun. 2010

LEFF, E (Coord.). A complexidade ambiental. São Paulo: Cortez. 2003. 342 p.

LOBATO, G; BORGHI, L. Análise estratigráfica da Formação Furnas (devoniano inferior) em afloramentos da borda leste da bacia do Paraná. $3^{\circ}$ Congresso Brasileiro de P\&D em Petróleo e Gás 2005. Disponível em: http://www.portalabpg.org.br/PDPetro/3/ trabalhos/IBP0392_05.pdf Acesso em 01 jun. 2010

Geografia Ensino \& Pesquisa, v. 16, n.2 p. 63 - 78, maio/ago. 2012

Prática de campo em paleo-rotas e o uso desta como proposta de ensino de Geociencias na educação básica
LOUREIRO, C. F. B. Trajetória e fundamentos da educação ambiental. 2 ed. São Paulo: Cortez, 2006.

MARCONI, M. A.; LAKATOS, E. M. Fundamentos de metodologia científica. 6 ed. São Paulo: Atlas, 2005.

MATSUMURA, W. M. K. Roteiro geológico nos Municípios de Castro e Tibagi, PR - Brasil. 2010, 191 f. Dissertação (Mestrado em Gestão do Território) Departamento de Geociências, Universidade Estadual de Ponta Grossa, Ponta Grossa, 2010. 
MELO, M.S de; GODOY, L. C; MENEGUZZO, P. M; SILVA, D. J. P da. A geologia no plano de manejo do Parque Estadual de Vila Velha, PR. Revista Brasileira de Geociências 2004. Disponivel em: http://ojs.c3sl.ufpr.br/ojs2/index.php/rbg/article/viewFile/10170/7299 Acesso em 01 jun. 2010

NEVES, J. P; CAMPOS, L. M. L.; SIMÕES, M. G. Jogos como recurso didático para o ensino de conceitos paleontológicos básicos aos estudantes do ensino fundamental. Revista Terra Plural, Ponta Grossa, v. 2, n. 1, p. 103-114, jan.jjul. 2008. Disponível em http://www.revistas.uepg. br/index.php?journal=tp\&page=article\&op=viewArticle\&path[ ]=392 Acesso em 01 jun. 2010

PALAIOS, G. - Paleontologia Estratigráfica. Universidade Estadual de Ponta Grossa. Disponivel em http://pluridata.sites.uol.com.br/pp/uepg.htm Acesso em 01 jun. 2010

QUINTAS, J. S. Educação no processo de gestão ambiental. In LAYRARGUES, P. P. (org.) Identidades da Educação Ambiental Brasileira. Brasília: MMA, 2004. p. 113-140.

SANTOS, Maria Eugenia de Carvalho Marchesini. Programa Levantamentos Geológicos Básicos do Brasil- PLGB. Paleontologia das Bacias do Parnaíba, Grajaú e São Luís/ Maria Eugênia de Carvalho Marchesini Santos [e] Marise Sardenberg Salgado de Carvalho- Rio de Janeiro : CPRM- Serviço Geológico do Brasil/DIEDIG/DEPAT, 2004. Disponível em: http://www.cprm.gov.br/ publique/media/Cap7.pdf Acesso em 01 jun. 2010

SCHEFFLER, Sandro Marcelo; FERNANDES, Antonio Carlos Sequeira. Blastoidea da formação Ponta Grossa (devoniano, bacia do Paraná), Estado do Paraná, Brasil. Arquivos do Museu Nacional, Rio de Janeiro, v.65, n.1, p.99-112, jan./mar.2007. Disponível em: http://acd.ufrj.br/ museuhp/CP/Arquivos/Arq.2007/Arq.651/Arqs $\% 2065 \% 281 \% 29 \% 20$ p.99112\%20Scheffler.pdf Acesso em 01 jun. 2010

SOUZA, R. S. de. Entendendo a questão ambiental: temas de economia, política e gestão do meio ambiente. Santa Cruz do Sul: EDUNISC, 2000.

TOLEDO, M. C. M.; MACEDO, A. B.; MACHADO, R.; MARTINS, V. T. S.; RICCOMINI, C.; SANTOS, P. R.; SILVA, M. E.; TEIXEIRA, W. Projeto de criação do curso de Licenciatura em Geociências e Educação Ambiental - Instituto de Geociências/USP. Geologia USP Publicação Especial, São Paulo, v. 3, p. 1-11, set. 2005. Disponível em http://geologiausp.icg.usp.br//downloads/ geoindex648.pdf Acesso em 01 jun. 2010

ZABINI, Caroline. Lingulídeos da sucessão devoniana da bacia do Paraná, Região dos Campos Gerais, Brasil: revisão de conceitos biológico-ecológicos e análise tafonômica básica. Volume I Porto Alegre, 2007. Universidade Federal do Rio Grande do Sul Instituto de Geociências Programa de Pós Graduação em Geociências. Dissertação de mestrado. Disponivel em: http://www.bibliotecadigital.ufrgs.br/da.php?nrb=000594878\&loc=200 7\&l=251a48905432c721 Acesso em 01 jun. 2010

Geografia Ensino \& Pesquisa, v. 16, n.2 p. $63-78$, maio/ago. 2012

Fernandes, F.; Okonoski, T. R. O.; Silva, I. N. O. 


\section{Correspondência:}

Fernando Fernandes - Universidade Estadual de Ponta Grossa. Av. Gal. Carlos Cavalcanti, 4.748, CIPP, Uvaranas, 84030-900, Ponta Grossa - PR-Brasil

E-mail: fernand_is@hotmail.com.

Recebido em 23 de maio de 2011.

Revisado pelo autor em 15 de março de 2012.

Aceito para publicação em 14 de julho de 2012. 